\title{
A Critical Analysis of Errors Made by Rural and Urban Students in ' $O$ ' Level Mathematics Paper 1 (4008/1) in Shurugwi and Gweru Districts, Zimbabwe
}

\author{
Silvanos Chirume \\ Zimbabwe Open University, Zimbabwe \\ Email: silvanoschirume [AT] yahoo.com
}

\begin{abstract}
This study critically investigated and analysed mathematical errors made by forty rural and urban Zimbabwe Ordinary Level students who wrote a test adopted from the ZIMSEC 2012 past examination paper (4008/1). Twenty students at a rural school in Shurugwi District and twenty students of similar characteristics (except for location or district) at an urban school in Gweru District were randomly sampled. Questions 1 and 7 (arithmetic and algebraic manipulations), 2 and 21 (psychomotor skills- measurement, shading, locus and geometric constructions) and 8 and 15 (word problems) were purposively sampled and students' written and marked scripts were subjected to a critical analysis of errors. The errors were classified into eight categories proposed by Dufresne (2012) and these were error in knowledge, error in skill, error in concept, error in making connections, error in strategy effectiveness, error in convention, error in process and error in format. Mixed methods (QUAL-quan, content and interpretivist) analyses of errors made by the rural students and those made by the urban students were made. The study offers possible strategies that teachers in rural and urban areas can use to rectify students' mathematical errors in the classroom situation and contributes to the body of knowledge on mathematical error analysis.
\end{abstract}

Keywords--- mathematical error, "O” Level students, rural students, urban students, types of errors, error analysis, error rectification

\section{INTRODUCTION}

According to Hirashima and Horiguchi (2016, p.2), "To Err is Human! In the process of learning and education, it is natural for students to make errors." However, in the classroom situation some teachers get angry and punish their students for making mathematical errors although the teachers themselves sometimes make similar errors on the chalkboard. Teachers should not forget that students do not make mathematical errors intentionally. Hence teachers and students should not point fingers at one another but should only be concerned when the errors are left uncorrected. Errors made should be pointed out and corrected so that they may not be repeated in future (Livingstone, 2015). It would appear that after marking students' written tests, most secondary school mathematics teachers in Zimbabwe seldom carry out a thorough analysis of the errors with an intention of using the results and findings as learning points. This study is intended to contribute to the body of knowledge on mathematical error analysis and rectification procedures in the Zimbabwean context.

\section{Statement of the problem}

After giving tests or examinations, most teachers mark them and record the marks and then go on to teach a new topic without analysing errors made in the previous topic. Also the Board of Examiners disseminate feedback on common mistakes in the ' $\mathrm{O}$ ' Level examination by reporting on correct and incorrect responses and not on the type of errors, leaving most teachers unable to employ error analysis and rectification as part of their teaching process. This may lead to students and teachers blaming each other for the poor achievement (Chirume \& Chikasha, 2014).

Purpose of the study

The purpose of this study is to critically investigate and analyse mathematical errors made by rural and urban Ordinary Level students who wrote a test adopted from the Zimbabwe School Examinations Council (ZIMSEC, 2012b) past examination paper (4008/1). Drawing on the review of related literature, the study also offers possible strategies that teachers in rural and urban areas could use to rectify students' mathematical errors in the classroom. 


\section{Research Questions}

The research questions for this study are:

1. What common errors and misconceptions do ' $\mathrm{O}$ ' Level students make in Mathematics Paper 1 (4008/1)?

2. How can the mathematical errors made by rural and urban ' $\mathrm{O}$ ' Level students be categorized?

3. Are there any differences in terms of quantity and quality of the errors made by rural and urban ' $\mathrm{O}$ ' Level students?

4. What are the possible reasons why the students make the errors?

5. How can the errors be rectified?

\section{Objectives of the study:}

The objectives of the study are:

- To analyse mathematical errors made by rural and urban Ordinary Level students who wrote a test adopted from the ZIMSEC 2012 past examination paper (4008/1) in Shurugwi and Gweru districts of Zimbabwe,

- To categorise the students' mathematical errors,

- To compare the errors made by rural and urban students in the two districts, and

- To offer possible strategies that the teachers can use to correct students' mathematical errors.

\section{Theoretical framework}

This study is based on the theory of 'assessment of mathematics learning' (Ernest, 2004). According to Ernest (2004, p. 209):

The theory of assessment is concerned to find measures of competence and positive achievement in mathematics without stereotyping students by ability, or

presupposing an hierarchical model of mathematics. Above all, it values fair assessment of competence, regardless of gender, race, class or other social variables, as well as the reduction of competition.

Zemelman, Daniels and Hyde (2005) list one of ten best practices for teaching mathematics and science as the 'use of assessment as a part of instruction.' Borrego and Henderson $(2014$, p. 20) also point out that, "Emphasis is on engaging and empowering faculty members to reflect on their teaching practice, frequently through consideration of assessment evidence, to make instructional changes based on their best judgment."

During assessment teachers usually find out that their students make errors. However, according to Lourens, Molefe and Brodie (2011), the errors made by learners make sense to those learners. Those errors may be a result of previous misconceptions which the learners have internalized. The misconceptions may lead to correct answers even when the thinking process that produces the answer is wrong. Hence Borasi (1987) cited in Lourens, Molefe and Brodie (2011), views errors as 'springboard of enquiry.' According to Lourens, Molefe and Brodie (2011), important issues for further exploration of mathematics can be raised through students' errors.

Because errors make sense to those who make them, it's important that errors be embraced in the teaching and learning of mathematics, and not be ignored, or merely corrected. It is also important to know how errors and misconceptions can inform our instructional practices. (Lourens, Molefe and Brodie, 2011, p. 2)

Error pattern analysis is an important methodological tool that the student-teacher should acquire during training and consistently use during teaching as part of his/her knowledge of content and teaching (KCT) and knowledge of content and students (KCS) (Ball, Thames, \& Phelps, 2008). KCS helps the teacher to anticipate student's errors and misconceptions and to deal with them. It also helps the teacher to rate students' exercises, design tasks and predict how students will do the tasks (Nyikahadzoyi, 2013). 


\section{Conceptual framework}

Eisenhart (1991) cited in Lester Jr. (2005, p.460) describes a conceptual framework as:

A skeletal structure of justification, rather than a skeletal structure of explanation. It is ... an argument that the concepts chosen for investigation, and any anticipated relationships among them, will be appropriate and useful given the research problem under investigation.

The conceptual framework guiding this study is that of defining and categorizing mathematical errors.

\section{Definition of terms}

The following terms which are not mutually exclusive are defined as they relate to this study.

Misconception: A misconception is lack of the correct concept or idea. Misconceptions may generate errors.

Error: According to Gardee and Brodie (2015, p.2), an error is a type of mistake. Errors are systematic. "They occur on a regular basis and are pervasive and persistent, often across contexts" ... and they "occur at a deeper conceptual level than slips."

Slip: A slip is a sporadic mistake made as a result of carelessness and which is easily rectified when pointed out. Slips are not symptoms of conceptual misunderstandings. "They usually occur because of particular learning characteristics possessed by a student (e.g. memory deficits, impulsivity, visual/motor integration problems)" (Error Pattern Analysis, n.d., pp. 2-3)

Mistake: A mistake is an answer or a doing that is a deviation from the expected or accepted result or action.

\section{Categorising errors}

Mathematical errors that students make may be categorized in various ways which may or may not be mutually exclusive. Elbrink (2008), on one hand, has categorized mathematical errors into calculation errors, procedural errors, and symbolic errors. For example, symbolic errors may be linked to or encompass language errors or interpretation errors while within the calculation errors or procedural errors one might pick up symbolic type of errors. Dufresne (2012, p. 1), on the other hand, outlines eight categories of errors that students usually make and defines them as follows:

Error in knowledge - lack of awareness of the basic facts, properties or principles,

Error in skill - mechanical errors in accuracy, incorrectly copying equations from one line to the next, often called careless or "stupid" mistakes,

Error in concept - there is a flaw in one's understanding or a misconception; these are usually fixed when there is an "Aha! Moment,"

Error in making connections - one understands two (or more) distinct concepts, but has a difficulty in putting those concepts together to make a connection and solve the problem,

Error in strategy effectiveness - there is a more efficient strategy (think of the Rule of Four) that would have taken less time to arrive, more completely, at the correct conclusion,

Error in convention - not following accepted practice, such as rounding errors, omitting units, incorrectly naming sets, etc.,

Error in process - not indicating sufficient or any work, such as defining variables, stating formulas or equations, showing relevant steps, not verifying work, omitting a conclusion/therefore statement, etc., and,

Error in format - writing illogical or inconsistent steps, poor usage of equals signs, arrows, writing scratch work in the middle of a solution, omitting limit notation, etc.

Each of Elbrink (2008)'s three categories may follow into one or more of Dufresne (2012)'s categories. For example, calculation errors may be related to 'error in process,' procedural errors may follow into 'error in skill' or 'error in 
process' while symbolic errors may be categorized into 'error in format.' In this study it is considered that Dufresne (2012)'s eight categories appear to be holistic and mutually exclusive and therefore the errors made by the rural and urban students in Shurugwi and Gweru districts were categorized according to these eight categories.

\section{Causes of students' errors}

This study considers students' errors to be caused by various factors which may be student-related, teacher-related, subject matter-related and ancillary factors-related.

The student-related factors may be due to student's anxiety and negative attitude towards mathematics, misunderstanding of important concepts, not grasping important skills, poor memory and lack of continuous practice.

The teacher-related factors may emanate from the technological, pedagogical and content knowledge (TPACK) Framework (Koehler, Mishra, Kereluik, Shin \& Graham, 2014). If the teacher lacks one or more of the different types of knowledge, then the student might make errors related to one or more of the knowledge types. The teacher might lack common content knowledge (CCK), specialized content knowledge (SCK), pedagogical knowledge (PK), knowledge of content and students (KCS), knowledge of curriculum (KC), knowledge of content and teaching (KCT), technological pedagogical knowledge (TPK), horizon content knowledge (HCK) (Ball, Thames \& Phelps, 2008) and other types of knowledge. HCK includes horizon knowledge that 'provides vision of content across its development' (Kessel, 2009), that is, how mathematics topics are connected from prior to future years. Apart from these knowledge types which a good teacher must possess, a teacher's personal attributes such as attitudes, behavior, voice projection, writing skill, and language might also cause students to make errors.

Subject matter-related or content factors such as inappropriately worded texts or wrongly spelt mathematics words or texts with too much jargon and confusing symbols might also cause students' errors. The subject matter should not be pitched at a far too high level for the student. Bingolbali, Akkoç, Ozmantar and Demir (2011, p. 47) call similar subject matter-related factors 'epistemological causes' which arise from the 'difficult nature of and abstractness of mathematical concepts.'

Ancillary factors which may cause students to make errors may be poor measuring and writing instruments, poor classroom environment, etc.

\section{Purpose of error analysis}

The main purpose of student error analysis is to finally correct the error and prevent, as far as possible, its repetition. Cohen and Spenciner (2007) list three processes in error analysis. These are error pattern identification, understanding why the errors are made and providing targeted instruction to correct the errors. According to Shalem, Sapire and Sorto (2014, p.1), “... teachers' involvement in error analysis of standardised and classroom assessment is no longer a professional right but a responsibility, an integral aspect of teacher knowledge." It appears that in the Zimbabwean context, many secondary school mathematics teachers insist that students should write their corrections before proceeding to do new work but few consider students' errors as a 'learning platform' for the whole class and error analysis as the teacher's professional responsibility.

\section{METHODOLOGY}

Twenty 'O' Level (Form 4) students at a rural school in Shurugwi District and twenty 'O' Level students of similar characteristics (except for location or district) at an urban school in Gweru District were randomly sampled. A test adopted from a ZIMSEC past 'O' Level Mathematics Paper 1 (4008/1 of 2012) was administered to the forty students. For the purpose of this research, Questions 1 and 7 (arithmetic and algebraic manipulations), Questions 2 and 21 (psychomotor skills- measurement, shading, locus and geometric constructions) and Questions 8 and 15 (word problems) were purposively selected for the error analysis. It was considered that these items covered the assessment objectives as stipulated in the Zimbabwe 'O' Level syllabus (ZIMSEC, 2012a). Mixed methods QUAL-quan (Ross \& Onwuegbuzie, 2012), content and interpretivist analyses of errors made by the rural students and those made by the urban students were made. In particular, an analysis of errors in the students' written scripts (content analysis of errors in the documents) was made followed by an interpretation and classification (interpretivist analysis) of those errors. Interpretivism in this study meant that learning was being interpreted and informed by the teacher-researcher (Luneta, 2015). 'QUAL-quan' meant the qualitative analysis dominated the quantitative analysis. Possible strategies for rectifying the errors were suggested. The study also compared rural and urban students' performances with the aim of testing previous research findings that rural students performed better in standardised tests than their urban counterparts (Chirume, 2012). 


\section{RESULTS}

\section{Quantitative Analysis}

Table 1: Showing $\%$ frequency of rural $(n=20)$ and $\%$ of urban $(n=20)$ students who made errors for each question

\begin{tabular}{|l|l|l|l|l|l|l|}
\hline & Question 1 & Question 2 & Question 7 & Question 8 & Question 15 & Question 21 \\
\hline Rural & $(40),[60],\{0\}$ & $(0),[85],\{15\}$ & $(20),[75],\{5\}$ & $(10),[85],\{5\}$ & $(0),[60],\{40\}$ & $(0),[5],\{95\}$ \\
\hline Total \% & 100 & 100 & 100 & 100 & 100 & 100 \\
\hline Urban & $(40),[55],\{5\}$ & $(10),[60],\{30\}$ & $(35),[55],\{10\}$ & $(15),[85],\{0\}$ & $(5),[45],\{50\}$ & $(20),[10],\{70\}$ \\
\hline Total \% & 100 & 100 & 100 & 100 & 100 & 100 \\
\hline
\end{tabular}

Key: figures in ( ) indicate \% for correct answer, figures in [ ] indicate \% for wrong answer while figures in \{\} indicate

$\%$ of students who did not answer the question.

Table 1 shows that for Questions 1, 2, 7 and 15, more students at the rural school made errors than students at the urban school. The same proportion of students (85\%) made errors on Question 8 while on Question 21 slightly more students at the urban school (10\%) than those at the rural school (5\%) made errors. It could be interesting to note that less than $50 \%$ of the rural as well as the urban students got correct answers for all the questions. These results might also confirm the assertion that students do not do well in ' $\mathrm{O}$ ' Level mathematics with the pass rate in the Midlands Province having being less than 25\% (Chirume, 2012; Chirume \& Chikasha, 2014). It also appears that Question 21 (on locus and geometric constructions) could have been more difficult to both groups since a large proportion (95\% rural and $70 \%$ urban) of students did not attempt it.

A t-test was then run using SPSS 16.0 to quantitatively compare the errors made by rural and urban students in the two districts. It was found that there were no significant differences (at $\alpha=0.05$ ) between the number of wrong answers made by the rural and urban students when answering the six questions $(\mathrm{t}=2.07, \mathrm{p}=0.093)$. There were also no significant differences between the number of questions which were not answered by the rural and urban students $(\mathrm{t}-0.14, \mathrm{p}=0.892)$. However, there were significant differences (in favour of urban students) between the number of correct answers made for each item by the rural and urban students $(\mathrm{t}=-3.05, \mathrm{p}=0.028)$.

A qualitative analysis then followed the quantitative analysis. The qualitative analysis was an analysis of errors in the students' written scripts (content analysis of errors in the documents) followed by an interpretation and classification (interpretivist analysis) of those errors. This was done to determine if there were any differences in terms of quality of the errors made by the rural and urban ' $\mathrm{O}$ ' Level students. 'Quality of errors' in this study refers to whether the errors were minor, severe, moderate, similar, or belonging to one or several categories.

\section{Qualitative Analysis Questions 1 and 7}

Question 1: Express 754.96 (a) correct to (i) 1 decimal place (ii) 1 significant figure, (b) in standard form.

\section{Observations/Findings:}

Students at the rural school made the following errors:

a(i) They counted 1 figure (decimal place) from the left side (wrong position) and just inserted the comma [754.96 =7.5]. Some just replaced 9 with 10 [754.96=754.10]. Others added 1 to 9 to make 10 but forgot to carry 1 to the units $[754.96=754.0]$

a(ii) Some students wrote 8 instead of 800 [754.96=8 to 1 sig fig]. Other students correctly counted one figure from the left side but did not consider whether the next figure was equal to or bigger than 5 so that they would increase the first figure by one [ $754.96=7.5$ or $754.96=7.5496]$. It seems the students did not know the meaning of significant figure.

(b) Some students did not know how to express a number in standard form or did not have an idea of the concept of 'standard form' [754.96=755 in standard form]. Others wrote a wrong index and put a decimal comma at a wrong position $\left[754.96=754.96 \times 10^{-2}\right]$. Some ignored the figures 5496 and wrote $7 \times 10^{-2}$. Some did not put a comma and left the other figures $\left[754.96=754 \times 10^{2}\right]$.

In comparison students at the urban school made the following errors on Question 1:

a(i) Some students had a correct result $\left[7549.6 \times 10^{-1}\right]$ but a wrong decimal place. They also made an error on addition facts [754.96 $=756.0$ to $1 \mathrm{dp}$, from $4+1=6$ instead of 5]. 
a(ii) Others confused the concept of decimal place with that of significant figure. They put a comma at the wrong place [754.96=7.5496 to $1 \mathrm{sf}]$.


while others made an error of omission $\left[7.5496^{2}\right.$ instead of $\left.7.5496 \times 10^{2}\right]$.

Errors made by both rural and urban students can be classified into conceptual errors, error in knowledge and error of omission. It was observed that students at both school types (rural and urban) made more or less the same error types.

Question 7: Solve the simultaneous equations $4 x+9 y=33,2 x-3 y=-6$

Observations/Findings:

The following errors were observed from the written scripts of rural students:

Wrongly adding unlike terms $[4 x+9 y=13 x]$, unable to add or subtract directed numbers $[2 x-3 y=1 x]$, disregarding unknowns $[13(x)+33(y) \Rightarrow x=46]$, wrongly copying $9 x$ instead of $9 y[4 x+9 x=33]$, wrongly adding coefficients and multiplying unknowns [13xy=33], wrong answer after division $\left[x=\frac{33}{13}=2.7\right]$, and wrongly exchanging signs on LHS of second equation $[-2 x+3 y=-6]$. They also made a rearrangement or subject of formula error $[33-4 x+9=y]$.

Some used matrices but added wrongly and got -70 instead of $-90\left[\left(\begin{array}{l}x \\ y\end{array}\right)=-\frac{1}{30}\left(\frac{-99+54}{-66-24}\right)=-\frac{1}{30}\left(\frac{-45}{-70}\right)\right]$. Some had wrong matrix entries $\left[\left(\begin{array}{ll}4 & 9 \\ 2 & 3\end{array}\right)\right.$ instead of $\left.\left(\begin{array}{cc}4 & 9 \\ 2 & -3\end{array}\right)\right]$. Others miscalculated the determinant $[12+18=30$, missing the minus sign]. Yet others made multiplication and division errors $\left[\frac{1}{30}\left(\begin{array}{l}186 \\ 165\end{array}\right) \Rightarrow\left(\begin{array}{l}x \\ y\end{array}\right)=\left(\begin{array}{l}2 \\ 3\end{array}\right)\right]$.

In comparison students at the urban school made the following errors on Question 7:

They wrongly added and/or subtracted unlike terms $\left[8 \mathrm{x}+6 \mathrm{y}=-39 \Rightarrow 14 \mathrm{y}=-39 ; 33-9 \mathrm{y}=4 \mathrm{x} \Rightarrow \frac{24 y}{4 y}=\frac{4 x}{4 y} ;-6+3 \mathrm{y}=2 \mathrm{x} \Rightarrow \frac{-6+2 x}{-3 y}\right.$ $\left.=\frac{-3 y}{-3 y}\right]$ and they chose wrong operation (+ instead of - ) to eliminate $x[-8 x+18 y=66,-8 x-12 y=-24 \Rightarrow 6 y=42]$. They made an incorrect change of subject of formula leading to wrong substitution $[y=2 x-3 y=6 \quad \therefore 4 x+9(2 x-3 y)=33 \Rightarrow 4 x+9(2 x-$ $3=6) 33 \Rightarrow 4 x+15 x=33+6 \Rightarrow 20 x=39]$, and they had wrong addition facts $[4 x+2 x=8 x, 4 x+15 x=20 x]$, wrong division facts $\left[\frac{20 x}{20}=\frac{39}{20} \Rightarrow \mathrm{x}=1.93\right.$ instead of $\left.\mathrm{x}=1.95\right]$, wrong multiplication facts [2(1.93)-3y=6 $\left.63.84-3 \mathrm{y}=6\right]$, and made incorrect multiplication of directed numbers $[(2 x-3 y=-6) x 4 \Rightarrow 8 x-12 y=24)]$ leading to substitution with a wrong answer].

It can be observed from the examples above that the students at the rural school made similar errors to those made by students at the urban school although those at the urban school did not use matrices to solve the simultaneous equations. The errors can be classified into error in skill, error in strategy effectiveness, error in process and error in format.

\section{Questions 2 and 21}

Question 2: (diagram drawn to scale on the actual question paper)

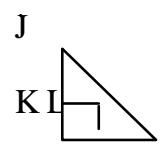

In the diagram, triangle JKL is right angled at K (a) Measure and write down (i) the length of KL correct to the nearest $\mathrm{cm}$ (ii) the size of KJL correct to the nearest degree (b) Write down the special name given to the side JL

\section{Observations/Findings:}

The following errors were observed from the written scripts of rural students:

(a) Six out of 20 students failed to correctly measure the length KL. They wrote $12 \mathrm{~cm}$ instead of $11 \mathrm{~cm}$. Ten out of 20 students failed to measure angle KJL. They wrote $90^{\circ}$ and $45^{\circ}$ instead of $61^{\circ}$.

(b) Six out of 20 students did not have an idea of the special name for side JL. They wrote 'opposite' instead of hypotenuse. Others (5 out of 20 ) knew the correct name but spelt it wrongly as 'hypothenus.' Ten of the students did not attempt to measure the angle nor the side while 3 students did not answer Question 2.

In comparison students at the urban school made the following errors on Question 2: 
(a) Two of the 20 students could not correctly measure the length of KL and 6 of the 20 students failed to measure angle KJL.

(b) Two out of 20 students did not have an idea of the special name given to side JL while 2 out of 20 students had an idea of the name but could not correctly spell it. The rest did well. Also two of the twenty students did not answer the question on length and another two out of twenty did not answer the question on angle. The rest of the students did well.

The errors made by both rural and urban students can be classified into error of knowledge (not knowing the hypotenuse), error in convention (wrong spelling) and error in 'psychomotor' skill (wrong measurements). It can also be concluded that both rural and urban students made similar errors.

Question 21: (drawn to scale on the actual question paper)

B

A

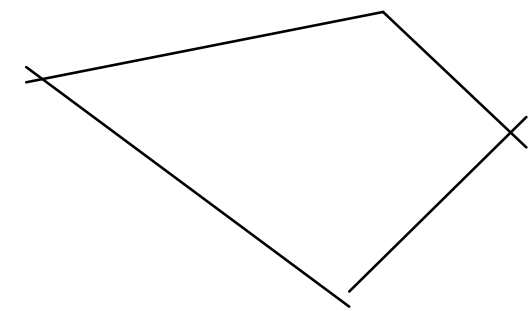

(a) In this question use ruler and compasses only. Leaving your construction lines and arcs, construct (i) the perpendicular bisector of $\mathrm{AB}$ (ii) the locus of all points inside the quadrilateral $\mathrm{ABCD}$ which are $5 \mathrm{~cm}$ from $\mathrm{D}$.

(b) Shade the region inside the quadrilateral $\mathrm{ABCD}$ which is nearer $\mathrm{A}$ than $\mathrm{B}$ and more than $5 \mathrm{~cm}$ from $\mathrm{D}$.

Observations/Findings:

(a) The main error made by one rural student was the inability to interpret the question and make appropriate ruler and compass constructions.

(b) This student answered 'quadilateral' (sic) which was a wrong answer.

The other 19 students did not answer the question.

In comparison students at the urban school made the following errors on Question 21:

(a) One out of 20 students could not interpret the question. Maybe he/she was baffled by the English language. One student made rough and incorrect construction lines and arcs.

(b) Three out of 20 students did not shade the required region.

Fourteen of the 20 students did not attempt the whole question.

These errors can be classified into error in knowledge, error in concept and error in format. It was also observed that more students at the rural school than at the urban school avoided this type of question. The reason why the students avoided the question could be that they did not have the measuring and construction instruments or that they were not confident enough in using their psychomotor skills.

\section{Questions 8 and 15}

Question 8: Jojo works in the afternoon only for 5 days a week. He starts work at $1.15 \mathrm{pm}$ and finishes at 7.45pm. (a) Express $7.45 \mathrm{pm}$ as time in the 24 - hour notation (b) If he is paid $\$ 1.20$ per hour, calculate his weekly wage.

\section{Observations/Findings:}

The following observations were noted on the scripts of rural school students:

(a) They could not correctly express $7.45 \mathrm{pm}$ in $24 \mathrm{hr}$ notation. Some wrote 19:45, some 1945pm and others 19:45hrs instead of 1945. In the new convention 'hrs', and ':' should not be written. In the $24 \mathrm{hr}$ notation pm or am should also not be written.

(b) Misinterpretation of the question: Some students misinterpreted the question and used the normal 7 days a week instead of 5 working days per week as stipulated. Miscalculation: Some students could not calculate the number of hours worked per day. Wrong multiplication facts and incorrect decimal placement: Some students failed to multiply numbers correctly while others misplaced the comma after multiplication. Wrong operation and wrong addition facts: Some 
students added 7.45 to 1.15 instead of subtracting and others added $\$ 1.20$ to $\$ 5$ and got $\$ 125$ or $\$ 6.20$ where they should have multiplied $\$ 1.20$ by 5 .

On the other hand, the following observations were noted on the scripts of urban school students:

(a) Wrong 24 hr notation [19:45 hrs of which ':' and 'hr' should not be put, some wrote 19.45pm]

(b) Misconception of equality and different units equated [1 $\mathrm{hr}=\$ 1.20]$, mixing common fractions and decimal fractions related to time resulting in wrong answer [writing $6 \frac{1}{2} \mathrm{hrs}$ as $6.30 \mathrm{hrs}$ instead of $6.50 \mathrm{hrs}$ ], misinterpretation of the question that could have been due to language or a 'slip' [multiplied 6- hrs by $\$ 11.20$ but failed to multiply again by 5 days and considered the usual 7 days a week instead of the implied 5 days per week], wrong subtraction facts [1945-1315=330 instead of 630], total confusion and multiple errors [1945-1315=3.30, then multiplying by 7 and then by 5 and by 120 ].

It can be observed that students from both rural and urban schools made similar errors on this question and the errors can be classified into error in knowledge (basic addition facts), error in skill (mechanical errors in accuracy), error in making connections (putting concepts together to make connections and then solving the problem), error in convention (not using accepted $24 \mathrm{hr}$ notation), and error in format (confusion and writing inconsistent steps).

Question 15: The mean of 10 numbers is 54.6. If the number $(x+6)$ is added to the 10 numbers, the mean becomes 51 . Find the value of $x$.

Observations/Findings:

Students at the rural school made the following errors:

Misinterpretation of the question: They used 54.6 as the sum of the numbers instead of it as the 'mean' of the ten numbers $[54.6+(x+6)=51 \Rightarrow x=16]$. Others formulated a wrong equation and were still unable to solve it $[x+6+10=51 \Rightarrow$ $x+6=61]$. Wrong operation: They multiplied instead of adding and divided by 6 or $6 x$ from nowhere $\left[\frac{54.6(x+6)}{6 x}=54 x\right.$, $\mathrm{x}=54]$. They added unlike terms $[\mathrm{x}+6+10=51 \Rightarrow 16 \mathrm{x}=51]$. In some cases it was difficult to follow what the student was thinking or doing $[54.6(x+6) \times 10=51,54.6=x=6]$. In such situations students' misconceptions/errors could have been better understood by asking them to talk or write about their work, computations or thinking processes.

In comparison students at the urban school made the following errors on Question 15

Misinterpretation of the question and misconception of 'mean' [e.g. 'added to the ten numbers' does not mean 'added to ten, $x+6+10=10, x+6+10=51, x+6=51, x=16+54.6, x=51$ or $x=45]$, wrong divisor 10 instead of 11 and different operations used on both sides of the equation $\left[\frac{552+x}{10}=51 \Rightarrow 552+x=5.1\right]$, considering 51 as the average of two numbers instead of 11 numbers $[x+6+54.6=51 \times 2 \Rightarrow x+6+54.6=102 \Rightarrow x+6=47.4 \Rightarrow x=41.4]$.

Similar errors were made by students at the rural and urban schools and the errors can be classified into error in skill, error in concept, error in strategy effectiveness and error in format.

\section{DISCUSSION}

In answering Research Question 1 (What common errors and misconceptions do ' $O$ ' Level students make in Mathematics Paper 1 (4008/1?), it would appear that most students first of all fail to interpret the question, probably due to language problems. This misinterpretation could lead them to make other errors such as the error of writing illogical or inconsistent steps or failure to make proper connections. The errors could be categorized in various ways but in this study Dufresne's categories were considered appropriate (Research Question 2).

In all the questions analysed above, it appears that the students made more or less the same type of errors. However and on average, students at the rural school made more errors than their urban counterparts although the difference was not statistically significant (Research Question 3). It was difficult to answer Research Question 4 since this study could not establish the reasons why the students made the errors nor why a larger number at the rural school made the errors. However, if the teachers and students were interviewed immediately after the students' scripts had been marked, perhaps the 'reasons behind these errors' as echoed by Lourens, Molefe and Brodie (2011) and Shalem, Sapire and Sorto (2014) could have been discovered. After reviewing related literature, it was speculated that if teachers were knowledgeable enough in error pattern analysis and rectification or correction techniques (Gardee \& Brodie, 2015) which they could regularly apply in the classrooms, the students could have made less errors. Teachers should not treat learner errors as 
'problems' but should consider them as 'learning opportunities' and avail chances for the learners to openly and freely discuss the errors or write about them (Elbrink, 2008). This partly answers Research Question 5.

In a previous study (Chirume, 2012) rural school students performed better in an 'O' level mathematics test than urban students. It could thus be interpreted that rural students made less mathematical errors than urban students. Although students in that previous study could have different characteristics with students in the current study, it seems that, in this study there was no sufficient evidence to confirm the results of the previous study.

Howell, Fox, and Morehead (1993) cited in Error Pattern Analysis (n.d) outline seven steps that teachers can follow when doing error pattern analysis. These are:

1. Collect a sufficient number of student computation samples for each type of problem you are interested in (at least 3 to 5 samples for each type of problem).

2. As the student works the problems, encourage him/her to talk aloud about what they are doing. Do not cue the student in any way.

3. Record all student responses, both written and verbal.

4. Review the responses and look for patterns among common problem types.

5. Also look for examples of "exceptions" to an apparent pattern (accurate "exceptions" may indicate that the student has partial understanding of the procedure or of a basic concept).

6. List in simple words the patterns you discover, then write beside each pattern why you think it is causing the student problems (e.g. if a student fails to regroup double digit addition problems, it may indicate that he does not understand the concept of place value).

7. Interview the student by asking her to explain how she solved the problem. Hearing what a student was thinking can help you confirm suspected error patterns and how they are impacting your student's success.

Error analysis should not just end at the 'analysis' level, but as suggested by Peng (2010) cited in Shalem, Sapire and Sorto (2014), it should include all the steps of identifying, addressing, diagnosing and correcting the errors. Thus two more steps could be added to the seven above. These could be re-teaching the concept or skill and then guiding the student to correct the error. For the teacher to be able to do error pattern analysis and to ultimately help students to correct 'their' errors, he or she should have certain attributes. These could be dedication to duty, creativity, innovativeness, professionalism, being economical with time and resources, and having the student at heart. He or she should also have a firm grasp of the different types of knowledge within the TPACK framework (Koehler, et al., 2014). The teacher should use the different types of knowledge within the TPACK framework to help him/her, “... to anticipate and resolve student errors and misconceptions, interpret incomplete student thinking, predict how students will handle specific tasks, and what students will find interesting and challenging (Nyikahadzoyi, 2013, p. 271). A limitation of this study is that it was not possible for the students to discuss the errors they had made in the test and the researcher and teachers did not have time to rectify the errors.

\section{CONCLUSION}

Based on the results and findings of this study, the following conclusions are made:

- Students at the rural school made more errors than those at the urban school as evidenced by the frequencies in Table 1. However, the difference was not statistically significant.

- The type of errors made by rural students and urban students were similar.

- Errors made by rural and urban students could be categorized in various ways. In this study it was possible to categorise the errors made by students at the rural and urban schools using Dufresne (2012)'s eight categories.

- Drawing from the review of related literature (Gardee \& Brodie, 2015, Error Pattern Analysis, n.d; Nyikahadzoyi, 2013), errors made by the students in the test could be rectified. 


\section{RECOMMENDATIONS}

The study recommends that:

- Further research on why students at the rural school seem to make more errors than those at the urban school should be carried out.

- Since rural and urban students made similar type of errors, one group of teachers or students should not blame the other group but errors should only be treated as an 'opportunity to learn.'

- During pre-service and in-service training, secondary school mathematics teachers should be thoroughly grounded on error analysis, categorization and rectification techniques.

- In order for mathematics teachers to have knowledge to correct students' errors, they should be thoroughly grounded in the TPACK framework.

\section{REFERENCES}

- Ball, D. L., Thames, M., \& Phelps, G. (2008). Content knowledge for teaching: What makes it special? Journal of Teacher Education 59(5), pp. 389-407. http://dx.doi.org/10.1177/0022487108324554

- $\quad$ Bingolbali, E., Akkoç, H., Ozmantar, M.F. \& Demir, S. (2011). Pre-Service and In-Service Teachers ${ }^{\text {ee }}$ Views of the Sources of Students ${ }^{\text {ee }}$ Mathematical Difficulties. International Electronic Journal of Mathematics Education $\mathrm{I} \Sigma \mathrm{JM} \Sigma 6,(1)$, pp. 40-59.

- Chirume, S. (2012). Reducing Mathematics Anxiety and Building Positive Attitudes: A Challenge For Teachers and Students. The Dyke, 6(1), pp.15-33.

- Chirume, S. \& Chikasha, A.S. (2014). A Critical Analysis of the Factors Affecting Achievement in Secondary School Mathematics in Zimbabwe: A Case Study of Gweru District. Merit Research Journal of Education and Review, 2(9), pp. 194-202.

- Cohen, L.G. \& Spenciner, L.J. (2007). Assessment of Children and Youth with Special Needs. Merrill, pp. 262263.

- Dufresne, R. (2012). Math 151 Error Analysis. Retrieved on 29/10/15 from http://people.qatar.tamu.edu/raelene.dufresne/education/math150/Math_150/Resources_files/erroranalysis.pdf

- $\quad$ Elbrink, M. (2008). Analyzing and Addressing Common Mathematical Errors in Secondary Education. [Extended Thesis Abstracts]. B.S. Undergraduate Mathematics Exchange, 5(1), pp. 1-4

- Ernest, P. (2004). The Philosophy of Mathematics Education. Routledge Falmer, Taylor and Francis e-Library, ISBN 0-203-49701-5 [Master e-book]

- $\quad$ Error Pattern Analysis, (n.d). Retrieved on from http://specialconnections.ku.edu/ specconn/page/instruction/math/pdf/patternanalysis.pdf

- $\quad$ Gardee, A., \& Brodie, K. (2015). A teacher's engagement with learner errors in her Grade 9 mathematics classroom. Pythagoras, 36(2), pp. 1-9. Retrieved on 8/04/16 from http://dx.doi.org/10.4102/pythagoras.v36i2.293

- Hirashima, T., \& Horiguchi, T. (2016). Creation of Cognitive Conflict by Error-Visualization: Error-Based Simulation and Its Practical Use in Science Learning. Springer International Publishing Switzerland, J.M. Spector et al. (eds.), Learning, Design, and Technology, DOI 10.1007/978-3-319-17727-4_9-1

- $\quad$ Kessel, C. (ed.) (2009). Teaching Teachers Mathematics: Research, Ideas, Projects, Evaluation. Mathematical Sciences Research Institute, Berkeley, California

- $\quad$ Koehler , M.J., Mishra, P., Kereluik, K., Shin, T.S., \& Graham, C.R. (2014). The Technological Pedagogical Content Knowledge Framework. In J.M. Spector, J.M. et al. (eds.), Handbook of Research on Educational 
Communications and Technology, Springer Science+Business Media New York, 101 DOI 10.1007/978-1-46143185-5_9.

- Lester Jr, F.K. (2005). On the theoretical, conceptual, and philosophical foundations for research in mathematics education. ZDM 37(6), pp. 457-467.

- Livingston, K.D. (2015). Correcting errors in the L2 classroom: students' and teachers' perceptions. Revista Electrónica del Lenguaje, (2), pp. 1-36.

- Lourens, R., Molefe, N. \& Brodie, K. (2011). Workshop: Error Analysis of Mathematics Test Items. Retrieved on 29/10/15 from http://directorymathsed.net/download/Lourens.pdf

- Luneta, K. (2015). Understanding students' misconceptions: An analysis of final Grade 12 examination questions in geometry. Pythagoras, 36(1), Art. \#261, 11 pages. Retrieved on 21/6/16 from http://dx.doi.org/10.4102/pythagoras.v36i1.261

- Nyikahadzoyi, M.R. (2013). Teachers' knowledge of the concept of a function: A theoretical framework. International Journal of Science and Mathematics Education 13 (Suppl 2): pp. 261-283.

- $\quad$ Ross, A. \& Onwuegbuzie, A.J. (2012). Prevalence of Mixed Methods Research in Mathematics Education. The Mathematics Educator, 22(1), pp. 84-113.

- Shalem, Y., Sapire, I., \& Sorto, M.A. (2014). Teachers' explanations of learners' errors in standardised mathematics assessments. Pythagoras, 35(1), pp. 1-11.

- Zemelman, S., Daniels, H., \& Hyde, A. (2005). Best practice: New standards for teaching and learning in America's school (3rd Edition). Portsmouth, NH: Heinemann.

- $\quad$ ZIMSEC (2012a). Zimbabwe General Certificate of Education (ZGCE) 'O’ Level Syllabus Mathematics 4008/4028. Retrieved on 21/04/15 from http://www.zimsec.co.zw/O_SYLLABUS/O-MATHEMATICS.pdf.

- $\quad$ ZIMSEC (2012b). Zimbabwe School Examinations Council: General Certificate of Education Ordinary Level Mathematics 4008/1 Paper 1 [Questions 1, 2, 7, 8, 15, and 21] ZIMSEC, Harare. 